\title{
Impact of nepafenac $0.1 \%$ on macular thickness and postoperative visual acuity after cataract surgery in patients at low risk for cystoid macular oedema
}

Department of

Ophthalmology, School of Medicine, University of North Carolina at Chapel Hill, Chapel Hill, NC, USA

Correspondence: KL Cohen, Department of

Ophthalmology, School of Medicine, University of North Carolina at Chapel Hill, 5100 Bioinformatics Building, 130 Mason Farm Road, CB no. 7040, Chapel Hill, NC 27599-7040, USA

Tel: + 1919966 5298;

Fax: + 19199661908

E-mail:klc@

med.unc.edu

Received: 12 October 2008 Accepted in revised form: 10 January 2009

Published online: 20

February 2009

Financial imterest: Kenneth C Mathys and Kenneth L Cohen have no financial interest.

This work was supported in part by Research to Prevent Blindness, Inc., New York, NY and presented at the ARVO 2008 Annual Meeting, Fort Lauderdale, FL, April-May 2008
Abstract

Purpose To evaluate the use of topical nepafenac $0.1 \%$ after routine phacoemulsification in patients at low risk for cystoid macular oedema (CME) using optical coherence tomography (OCT) measurement of macular thickness.

Methods Seventy-nine subjects with no risk factors for CME had uncomplicated bimanual micro-incision cataract surgery by an experienced surgeon. All subjects received preoperative nepafenac. Subjects were randomised to postoperative standard of care, consisting of a topical antibiotic for $\mathbf{1 0}$ days and topical corticosteroid for 1 month (control), or standard of care plus nepafenac for 1 month (treatment). OCT and ETDRS best-corrected visual acuity were measured preoperatively and 2 months postoperatively. Primary endpoints were comparison of changes in macular thickness between groups and the relationship of that change to postoperative vision.

Results All subjects had excellent visual outcomes, with mean visual improvement of 15 letters. Cataract surgery was very efficient with a mean effective phaco time (EPT) of 4.99 and $6.90 \mathrm{~s}$ in the control and treatment groups, respectively. There were small increases in the central macular thickness in both the control $(2.78 \mu \mathrm{m})$ and treatment $(5.60 \mu \mathrm{m})$ groups. The change in macular thickness was statistically similar between groups and did not correlate with the final visual outcome.
Discussion The small increase in macular thickness after routine cataract surgery is probably not clinically significant. In subjects undergoing routine cataract surgery, and at low risk for $\mathrm{CME}$, the routine use of preoperative nepafenac may be all that is necessary to achieve excellent visual recovery. Eye (2010) 24, 90-96; doi:10.1038/eye.2009.10; published online 20 February 2009

Keywords: cataract surgery; NSAID; cystoid macular oedema

Introduction

Although cystoid macular oedema (CME) is thought to be the leading cause of decreased vision after phacoemulsification, the incidence is not well documented. ${ }^{1} \mathrm{~A}$ recent retrospective study of ophthalmology resident operations found an incidence of $<2 \%$, when diabetics were excluded. ${ }^{2}$ In contrast, two prospective studies did not show CME causing decreased vision, even with a $9 \%$ increase in the mean foveal thickness measured with optical coherence tomography (OCT) and a 9\% incidence of angiographic CME at 6 weeks after surgery.,4

It is suggested that, as standard of care after phacoemulsification, a topical NSAID should be used preoperatively and postoperatively to promote the rapid and complete recovery of visual acuity. ${ }^{1,5}$ Studies commonly cited to support this recommendation used 
intracapsular and extracapsular surgery; therefore, the application of these studies to current phacoemulsification techniques is questionable. ${ }^{5,6}$ To our knowledge, the only prospective study supporting this statement is Miyake's study, because this study measured visual acuity and assessed for macular oedema in all subjects. ${ }^{7}$ To help define standard of care for the use of a topical NSAID after routine phacoemulsification, our prospective, randomised study evaluated best-corrected visual acuity (BCVA) and macular thickness measured by OCT.

\section{Materials and methods}

All patients scheduled for phacoemulsification with posterior chamber IOL lens implantation, who agreed to participate and who met the inclusion and exclusion criteria, were consecutively enrolled in this randomised, non-masked, parallel-group clinical trial.

\section{Ethics review and registration of trial}

This study was approved by the Institutional Review Board at the University of North Carolina (no. 05-3115) and registered at http://www.clinicaltrials.gov (NCT00494494) according to the standards set by the International Committee of Medical Journal Editors and the World Health Organization. After receiving an explanation of all procedures, and before their enrolment, all patients provided written informed consent.

\section{Study protocol}

The planned enrolment was 80 subjects with a $1: 1$ control : treatment ratio. Inclusion criteria for the study were patients planning to have cataract surgery by KLC at the Ambulatory Care Center, the University of North Carolina Hospitals. Exclusion criteria included factors that could increase the risk of post-cataract $\mathrm{CME}$, including medically treated diabetes mellitus, history of uveitis, use of topical prostaglandin analogues for glaucoma, history of earlier intraocular surgery in the same eye, retinal vascular disease, and macular degeneration. Patients with abnormal preoperative OCT measurements were excluded.

Subjects were randomised according to the even/odd subject identification number, using computer-generated random numbers, to the control group (standard of care only) or the treatment group (standard of care plus nepafenac). Preoperatively, all cataracts were graded using LOCS III, ETDRS BCVA was measured, and OCT scans were carried out. ${ }^{8}$

All subjects received nepafenac $0.01 \%$ drops in the operated eye thrice, $5 \mathrm{~min}$ apart, immediately before surgery to maintain pupillary dilation. All subjects had bimanual microincision cataract surgery (MICS) using the Infiniti platform (Alcon Inc. Ft. Worth, TX, USA) and injection of an AR40e IOL (Advanced Medical Optics, Inc., Santa Ana, CA, USA) into the capsular bag was performed by KLC. ${ }^{9}$ Intraoperative phacoemulsification parameters, phaco time (PT), average \% phaco power (PP), and average power in foot position three (APFP3), were recorded. Effective phaco time (EPT) was calculated by multiplying PT with PP. ${ }^{10}$

Postoperatively, eyes received moxifloxacin $0.5 \%$ four times a day for 10 days and prednisolone acetate $1 \%$ four times a day for 1 month. Eyes in the treatment group also received nepafenac $0.1 \%$ thrice a day for 1 month.

Postoperative follow-up was at 1 day, 1 week, 1 month, and 2 months. At the 2 months visit, technicians, who were masked to treatment, measured ETDRS BCVA, and OCT scans were performed.

\section{Optical coherence tomography}

Experienced ophthalmic photographers, who were masked to treatment, obtained Stratus OCT (Carl Zeiss Meditec, Inc., San Francisco, CA, USA) scans using the fast macular thickness protocol. The foveal thickness $(\mu \mathrm{m})$ (intersection of the six radial scans), macular thickness $(\mu \mathrm{m})$ (central $1 \mathrm{~mm}$ diameter centred on the fovea), and total macular volume $\left(\mathrm{mm}^{3}\right)$ measurements were recorded. The quality of all scans was reviewed by observation of foveal centration and signal strength. Scans that were thought to be unreliable were excluded from the analysis.

\section{Study endpoint}

The endpoints of the study were change in macular thickness measured by OCT in the central $1 \mathrm{~mm}$ diameter centred on the fovea (central macular thickness), fovea (foveal thickness), total macular volume, and BCVA 2 months postoperatively.

\section{Statistical analysis}

Power calculation was carried out using pilot data from our study. Standard methods were used for power calculation to determine the sample size needed to have 0.90 power for the comparison between two groups at the two-sided significance of 0.05 .

Data were entered into a Microsoft Excel spreadsheet and analysed using SAS (SAS-PC 9.1.2, SAS Institute, Cary, NC,USA) by an independent biostatistician. Between-group comparisons were conducted using the Wilcoxon signed rank-sum test for numerical variables and the Pearson $\chi^{2}$-test for categorical variables. The 
paired $t$-test was used for within-subject before-after surgery comparison. The Spearman correlation coefficient was used to evaluate relationships between postoperative BCVA and OCT measurements. All tests were two-sided with $95 \%$ confidence level.

\section{Results}

One eye of each of the 84 subjects was enrolled in the study, and all had uncomplicated MICS and completed follow-up. There were no adverse events reported by patients using nepafenac. Forty-two subjects were randomised to each arm of the study. Three subjects in the treatment group and two subjects in the control group had unreliable preoperative OCT scans because of dense posterior subcapsular cataracts. These subjects were excluded from the analysis. Therefore, 79 eyes of 79 subjects, 39 in the treatment group and 40 in the control group, were included in the statistical analyses.

Thirty-seven males and 42 females were in the study. The gender distribution was similar in both groups $(P=0.9046)$. The mean age of patients in the treatment group was slightly greater than that in the control group, 73.95 and 70.33 years, respectively $(P=0.0460$, Table 1$)$. BCVA and OCT testing were carried out from 50 to 146 days after surgery. The mean time to follow-up was 73.31 days ( $\pm 21.58 \mathrm{SD}$, range 55-146) in the treatment group and 68.98 days ( \pm 13.98 , range $50-120$ ) in the standard-ofcare group. The time to follow-up was statistically comparable between groups $(P=0.4796$, Table 1$)$.

Table 1 Comparison of demographic and clinical characteristics

\begin{tabular}{|c|c|c|c|}
\hline Variable & $\begin{array}{c}\text { Standard }+ \text { nepafenac } \\
(\mathrm{n}=39)\end{array}$ & $\begin{array}{l}\text { Standard of care } \\
\quad(\mathrm{n}=40)\end{array}$ & P-value \\
\hline \multicolumn{4}{|l|}{ Age (years) } \\
\hline Mean (SD) & $73.95 \pm 8.99$ & $70.33 \pm 8.04$ & 0.0460 \\
\hline Range & $51-90$ & $44-88$ & \\
\hline \multicolumn{4}{|l|}{ Gender } \\
\hline Male & $18(46.15 \%)$ & $19(47.50 \%)$ & 0.9046 \\
\hline Female & $21(53.85 \%)$ & $21(52.50 \%)$ & \\
\hline \multicolumn{4}{|c|}{ Pre-op VA (letters) } \\
\hline Mean $\pm S D$ & $40.49 \pm 9.56$ & $38.48 \pm 9.83$ & 0.1937 \\
\hline Range & $3-55$ & $10-55$ & \\
\hline \multicolumn{4}{|c|}{ Follow-up time (days) } \\
\hline Mean \pm SD & $73.31 \pm 21.58$ & $68.98 \pm 13.98$ & 0.4796 \\
\hline Range & $55-146$ & $50-120$ & \\
\hline
\end{tabular}

$P$-values of the two-sided Wilcoxon rank-sum test for numeric variables or of the two-sided Pearson $\chi^{2}$-test for categorical variables for betweengroup comparison.
Cataract classification and surgical parameters are listed in Table 2. One subject in each group did not have a preoperative LOCS III measurement recorded. Subjects had relatively dense cataracts as described by nuclear colour (NC) and nuclear opalescence (NO). Mean NC in the treatment group was 4.00 ( $\pm 0.94 \mathrm{SD}$, range 2.7-5.9) and that in the control group was $3.82( \pm 0.89 \mathrm{SD}$, range 2.6-5.9) $(P=0.3969)$. Mean NO in the treatment group was 4.04 ( $\pm 0.88 \mathrm{SD}$, range $2.7-5.9)$ and that in the control group was 3.81 ( $\pm 0.85 \mathrm{SD}$, range $2.6-5.7)(P=0.2526)$.

The LOCS III classifications were statistically comparable between groups (Table 2).

All subjects had uncomplicated MICS and implantation of a posterior chamber IOL in the capsular bag. ${ }^{9}$ Mean EPT in the treatment group was $6.90 \mathrm{~s}( \pm 4.57$ $\mathrm{SD}$, range 0.34-18.47) and mean EPT in the control group was $4.99 \mathrm{~s}$ ( $\pm 4.16 \mathrm{SD}$, range 0.05-15.27). The PT and

Table 2 Comparison of clinical and surgical parameters

\begin{tabular}{lccc}
\hline Variable & $\begin{array}{c}\text { Standard }+ \\
\text { nepafenac } \\
(\mathrm{n}=39)\end{array}$ & $\begin{array}{c}\text { Standard of } \\
\text { care }(\mathrm{n}=40)\end{array}$ & P-value \\
\hline $\begin{array}{l}\text { Nuclear colour } \\
\text { Mean } \pm \text { SD }\end{array}$ & $4.00 \pm 0.94$ & $3.82 \pm 0.89$ & 0.3969 \\
$\quad$ Range & $2.70-5.90$ & $2.60-5.90$ & \\
& & & \\
Nuclear opalesence & & & \\
$\quad$ Mean \pm SD & $4.04 \pm 0.88$ & $3.81 \pm 0.85$ & 0.2526 \\
$\quad$ Range & $2.70-5.90$ & $2.60-5.70$ &
\end{tabular}

Posterior subcapsular cataract

$\begin{array}{llll}\text { Mean } \pm \text { SD } & 1.16 \pm 1.33 & 1.19 \pm 1.49 & 0.5763 \\ \text { Range } & 0.00-5.50 & 0.00-5.60 & \end{array}$

Cortical cataract

Mean \pm SD $\quad 2.25 \pm 1.49 \quad 1.87 \pm 1.38 \quad 0.2155$

Range

$0.00-5.90 \quad 0.00-5.90$

Phaco time (s)

Mean \pm SD

Range

$14.88 \pm 9.89 \quad 10.48 \pm 8.34$

0.0357

Average phaco power (\%)

Mean \pm SD $\quad 45.88 \pm 5.15 \quad 45.51 \pm 5.73$

Range $\quad 28.60-50.50 \quad 27.10-52.10$

0.6012

Average power in foot

position $3(\%)$

Mean \pm SD

Range

$6.52 \pm 2.21 \quad 5.52 \pm 2.34 \quad 0.0697$

$1.60-11.80 \quad 0.70-10.90$

Effective phaco time (s)

Mean \pm SD

$6.90 \pm 4.57 \quad 4.99 \pm 4.16$

0.0387

Range

$0.34-18.47 \quad 0.05-15.27$

$P$-values of the two-sided Wilcoxon rank-sum test for between-group comparisons. 
EPT in the treatment group were slightly greater than those in the control group $(P=0.0357, P=0.0387)$. Mean APFP3 in the treatment group was $6.52 \%( \pm 2.21 \mathrm{SD}$, range 1.60-11.80) and mean APFP3 in the control group was $5.52 \%( \pm 2.34 \mathrm{SD}$, range $0.70-10.90)$, with no difference between groups $(P=0.0697)$. The PP was not different between groups $(P=0.6012)$.

Both groups had excellent postoperative BCVA (Table 3). Mean preoperative BCVA was not different between groups $(P=0.1937)$. Mean BCVA improvement was 15.00 letters in the treatment group and 15.98 letters in the control group. There was no difference between groups in the final BCVA outcome $(P=0.5005)$.

OCT measurements are listed in Table 4. All eyes had normal preoperative OCT scans. Preoperative OCT

Table 3 Comparison of visual acuity, ETDRS

\begin{tabular}{|c|c|c|c|c|c|}
\hline \multirow[t]{2}{*}{ Time } & \multicolumn{2}{|c|}{$\begin{array}{c}\text { Standard + nepafenac } \\
(\mathrm{n}=39)\end{array}$} & \multicolumn{2}{|c|}{$\begin{array}{l}\text { Standard of care } \\
\qquad(\mathrm{n}=40)\end{array}$} & \multirow[t]{2}{*}{ P-value } \\
\hline & $M e a n \pm S D$ & Range & $M e a n \pm S D$ & Range & \\
\hline Pre-op VA & $40.49 \pm 9.56$ & $3-55$ & $38.48 \pm 9.83$ & $10-55$ & 0.1937 \\
\hline Post-op VA & $55.49 \pm 5.64$ & $44-65$ & $54.46 \pm 5.43$ & $39-67$ & 0.5005 \\
\hline
\end{tabular}

measurements of foveal thickness, central macular thickness, and macular volume were statistically comparable between groups $(P=0.1877, P=0.2294$, $P=0.5257)$. At the final follow-up visit, the postoperative OCT measurements of foveal thickness, central macular thickness, and macular volume were also statistically comparable between groups $(P=0.6322, P=0.4913$, $P=0.3828)$. The average change in macular thickness was small in both groups. Mean change in central macular thickness in the treatment group was $5.6 \mu \mathrm{m}$ ( \pm 13.8 SD, range $-34.0-43.0$ ) and thatin the control group was $2.78 \mu \mathrm{m}$ ( $\pm 12.9 \mathrm{SD}$, range $-26.0-26.0)$. For all OCT measurements, there were no differences in the change from preoperative to postoperative measurements between groups (Table 4).

On the basis of the mean change in central macular thickness in the control and treatment groups of \pm 12.9 and $\pm 13.8 \mu \mathrm{m}$, respectively, a conservative estimate of variability of the change in macular thickness is $\pm 15 \mu \mathrm{m}$. Our estimate of a clinically relevant increase is $25 \mu \mathrm{m} .{ }^{11}$ With these specifications, the sample size that is required to have 0.90 power for the comparison between two groups at the two-sided 0.05 significance level is about 10 per group. The small number needed to detect a significant difference is because of the fact that the estimated clinically relevant difference is almost double the estimate of variability. Thus, our study was powered appropriately to detect a significant difference between groups.

Table 4 Comparison of OCT parameters

\begin{tabular}{|c|c|c|c|c|c|}
\hline & \multicolumn{2}{|c|}{ Standard + nepafenac } & \multicolumn{2}{|c|}{ Standard of care } & \multirow[t]{2}{*}{ P-value } \\
\hline & Mean $\pm S D$ & Range & Mean $\pm S D$ & Range & \\
\hline \multicolumn{6}{|l|}{ Pre-op } \\
\hline Central macular thickness $(\mu \mathrm{m})$ & $211.2 \pm 29.15$ & $154.0-287.0$ & $214.5 \pm 25.52$ & $156.0-259.0$ & 0.2294 \\
\hline Foveal thickness $(\mu \mathrm{m})$ & $181.7 \pm 34.5$ & $122.0-281.0$ & $189.5 \pm 30.5$ & $136.0-252.0$ & 0.1877 \\
\hline Macular volume $\left(\mathrm{mm}^{3}\right)$ & $6.58 \pm 0.41$ & $5.62-7.57$ & $6.63 \pm 0.47$ & 5.43-7.39 & 0.5257 \\
\hline \multicolumn{6}{|l|}{ Follow-up } \\
\hline Central macular thickness $(\mu \mathrm{m})$ & $216.8 \pm 32.6$ & $161.0-305.0$ & $217.2 \pm 27.2$ & $144.0-278.0$ & 0.4913 \\
\hline Foveal thickness $(\mu \mathrm{m})$ & $186.4 \pm 37.4$ & $126.0-293.0$ & $187.5 \pm 30.9$ & $115.0-274.0$ & 0.6322 \\
\hline Macular volume $\left(\mathrm{mm}^{3}\right)$ & $6.68 \pm 0.36$ & $5.61-7.80$ & $6.68 \pm 0.73$ & $3.24-7.55$ & 0.3828 \\
\hline \multicolumn{6}{|l|}{ Changes } \\
\hline Central macular thickness $(\mu \mathrm{m})$ & $5.6 \pm 13.8$ & $-34.0-43.0$ & $2.78 \pm 12.9$ & $-26.0-26.0$ & 0.7029 \\
\hline Foveal thickness $(\mu \mathrm{m})$ & $4.7 \pm 19.6$ & $-40.0-56.0$ & $-2.0 \pm 23.4$ & $-62.0-45.0$ & 0.5066 \\
\hline Macular volume $\left(\mathrm{mm}^{3}\right)$ & $0.10 \pm 0.21$ & $-0.44-0.65$ & $0.05 \pm 0.51$ & $-2.82-0.56$ & 0.5099 \\
\hline \multicolumn{6}{|l|}{$\%$ Changes } \\
\hline Central macular thickness $(\mu \mathrm{m})$ & $2.68 \pm 6.58$ & $-16.35-19.63$ & $1.40 \pm 6.05$ & $-12.75-13.25$ & 0.6922 \\
\hline Foveal thickness $(\mu \mathrm{m})$ & $2.96 \pm 10.88$ & $-22.60-37.09$ & $-0.38 \pm 12.00$ & $-24.60-30.88$ & 0.3989 \\
\hline Macular volume $\left(\mathrm{mm}^{3}\right)$ & $1.60 \pm 3.29$ & $-6.08-10.85$ & $0.68 \pm 8.24$ & $-46.53-8.78$ & 0.5450 \\
\hline
\end{tabular}

$P$-values of the two-sided Wilcoxon rank-sum test for between-group comparisons.

Changes $=$ follow-up thickness/volume-baseline thickness/volume of the same eye. A negative number indicates a decrease in thickness/volume. $\%$ Changes $=100 \times($ follow-up thickness/volume-baseline thickness/volume)/baseline thickness/volume. A negative number indicates a decrease in thickness/volume. 
Table 5 Correlations between $\%$ change in OCT and post-op VA

\begin{tabular}{lrrr}
\hline Parameters & \multicolumn{3}{c}{ \% change from pre-operative OCT } \\
\cline { 2 - 4 } & $\begin{array}{c}\text { Central macular } \\
\text { thickness }\end{array}$ & $\begin{array}{c}\text { Fovea } \\
\text { thickness }\end{array}$ & $\begin{array}{c}\text { Macular } \\
\text { volume }\end{array}$ \\
\hline Post-op VA standard of care & 0.0247 & 0.0464 & -0.0023 \\
& 0.8816 & 0.7793 & 0.9889 \\
Post-op VA standard of & -0.1773 & -0.1849 & -0.0545 \\
care + nepafenac & 0.2803 & 0.2598 & 0.7417 \\
\hline
\end{tabular}

Note: The first row indicates coefficients based on the Pearson productmoment correlation, and the second row indicates the $P$-values of the correlations under the null hypothesis of no correlation.

Correlations between OCT measurements and postoperative BCVA are listed in Table 5. There were no correlations between OCT measurements and BCVA in either group.

\section{Discussion}

Our prospective, randomised study evaluated the effects of a postoperative NSAID on OCT measurements of macular thickness, and BCVA in low-risk patients who had uncomplicated phacoemulsification. We chose nepafenac, because it is a prodrug that may be more efficacious and safer than non-prodrug NSAIDs. ${ }^{12,13}$ The most important findings of our study are that after MICS there were no differences between the treatment group and the control group regarding foveal thickness, central macular thickness, total macular volume, and BCVA (Tables 3 and 4).

Increased OCT-measured macular thickness after phacoemulsification is well documented. When preoperative and postoperative OCT measurements were compared, $27-41 \%$ of eyes had increased macular thickness at 6-8.5 weeks after surgery. ${ }^{11,14}$ At 30 weeks after surgery, $22 \%$ of eyes had increased macular thickness. ${ }^{11}$ A more recent study confirmed increased macular thickness at 6 months postoperatively. ${ }^{15}$ Two prospective studies that controlled for intraindividual difference in macular thickness showed similar results. $^{4,16}$

An important clinical issue is the effect of a postoperative NSAID on this increase in macular thickness. Prospective studies evaluated the effect of a postoperative NSAID on the development of macular oedema after phacoemulsification. ${ }^{7,17-19}$ At 5 weeks after phacoemulsification, Miyake's study documented 5.7 vs $54.7 \%$ angiographic CME in the eyes that received only diclofenac $0.1 \%$ vs the eyes that received only flurometholone $0.1 \%$, respectively. ${ }^{7}$ Two recent studies confirmed these findings when an NSAID was used preoperatively and postoperatively. ${ }^{17,18}$ When ketorolac
$0.5 \%$ and prednisolone $1 \%$ were compared with prednisolone $1 \%$ alone, a lower total macular volume was found in the ketorolac group at 1 month postoperatively. ${ }^{17}$ When diclofenac $0.1 \%$ alone was compared with betamethasone $0.1 \%$, angiographic CME was $18.8 \%$ in the diclofenac group vs $58.0 \%$ in the betamethasone group at 5 weeks postoperatively. ${ }^{18}$ Donnenfeld's study also used ketorolac preoperatively and postoperatively. However, Donnenfeld's study only performed OCT scans to diagnose macular oedema when BCVA was $<20 / 30$ and therefore does not provide the incidence of macular oedema in the ketorolac and the non-ketorolac groups. ${ }^{19}$ Without considering BCVA data, these studies support the postoperative use of an NSAID.

Although the peak incidence of CME is said to be at 4-12 weeks after surgery, we may have missed the time course for detecting the maximum increased OCT measured macular thickness. ${ }^{20}$ Our goal was to have follow-up at 60 days postoperatively; owing to subject compliance, mean follow-up was 70 and 69 days in the treatment group and the control group, respectively (Table 1). After routine phacoemulsification, OCTmeasured macular thickness increase seems to peak at 4-6 weeks postoperatively. ${ }^{4,11,15,16}$ However, importantly, there is evidence that after phacoemulsification, the OCT-measured macular thickness can be increased from 60 days to 6 months postoperatively. ${ }^{11,14-16}$ Therefore, the follow-up in our study was likely to be adequate enough to have detected a difference between the groups at the final postoperative examination.

Another important clinical issue after routine phacoemulsification is the effect of increased macular thickness on BCVA. Our study supports evidence that the increase in OCT-measured macular thickness after routine phacoemulsification in subjects with a low risk of CME is small and has no clinical effect on visual acuity (Tables 4 and 5). In these earlier studies, postoperative visual acuity was excellent immediately after surgery, and BCVA was not correlated with macular thickness, similar to our study (Table 5).,15,16 Therefore, if our study missed the peak increase in macular thickness, the increase in macular thickness after MICS in our study population was unlikely to have adversely affected final BCVA. The BCVA after MICS in low-risk patients for CME is excellent. ${ }^{9,21,22}$ There is evidence that after coaxial phacoemulsification, BCVA in the first 2 weeks postoperatively improves with the use of postoperative NSAID. ${ }^{7}$ Our study did not measure BCVA during the first 2 postoperative weeks.

All subjects in the control and treatment groups received preoperative nepafenac. In patients with no risk factors for $\mathrm{CME}$, this may be the dosing strategy necessary to prevent postoperative macular thickening. Our patients had MICS, but it is unlikely that the surgical 
technique affected our results. Earlier studies comparing MICS and coaxial cataract surgery showed similar operative metrics, or metrics suggesting that MICS was slightly more efficient. ${ }^{21,22}$ In our study, although the cataracts were equally dense in both the treatment and control groups, the treatment group had more PT and EPT (Table 2). EPT is derived directly from a calculation using PT and PP. Thus EPT was in range for uncomplicated MICS, and because PP may be associated with increased OCT measured macular thickness, we do not think that the difference in EPT affected our results and conclusions. ${ }^{21,22,23}$ Although the subjects who received the postoperative NSAID were older, the mean ages of our study groups are typical for patients undergoing cataract surgery, and therefore we do not think that the age difference affected our results and conclusions (Table 1).

Our study found a small percentage increase in macular thickness after MICS (Table 4), similar to earlier studies, which found increases of 3.5-6\%.,15,16 These small increases could have been missed by our study because of the documented reproducibility of $\pm 5 \%$ in normal subjects and SDs of $24 \mu \mathrm{m}$ preoperatively, and at up to 8 weeks after phacoemulsification. ${ }^{24,25}$ As there was no statistical difference in macular thickness between the treatment and control groups, and because $25 \mu \mathrm{m}$ was taken as the clinically relevant increase in macular thickness, no conclusions can be drawn regarding the greater increase in central macular thickness in the treatment group compared with the control group. ${ }^{11}$

A recent multicentre randomised clinical trial by Wittpenn, et al studied the effect of ketorolac $0.4 \%$ and prednisolone acetate $1 \%$ vs prednisolone acetate alone after uncomplicated cataract surgery in patients at low risk for $\mathrm{CME}^{26}$ This study supports the use of a preoperative and postoperative NSAID to minimise an increase in OCT-measured macular thickness. The results showed significantly increased OCT-measured macular thickness in the steroid group $(9.6 \mu \mathrm{m})$ vs the ketorolac/ steroid group $(3.9 \mu \mathrm{m})$ at 4 weeks after surgery. Also, the incidence of 'probable' or 'definite' CME based on masked interpretation of OCT images was higher in the steroid group $(2.4 \%)$ than in the ketorolac/steroid group $(0 \%)$. Subjects in both groups had excellent final BCVA. There was no difference between the groups for BCVA worse than 20/40, or contrast sensitivity.

Wittpenn's study examined a population at low risk for CME, similar to our study population, and found a significant increase in OCT-measured macular thickness, which our study did not find. ${ }^{26}$ An explanation for this difference is that our study evaluated macular thickness at approximately 8 weeks vs 4 weeks in Wittpenn's study. Thus, we may have missed measuring the maximum retinal thickness. Also, all subjects in our study received a preoperative NSAID, while the control group in Wittpenn's study did not. Wittpenn found a mean change in retinal thickness of $3.9 \mu \mathrm{m}$ in the group that received the NSAID, which is similar to the $2.78 \mu \mathrm{m}$ increase in our control group, suggesting that a preoperative NSAID may be all that is necessary to minimise an increase of retinal thickness in low-risk patients. It is most important to note that in both our study and in Wittpenn's study, all subjects had excellent visual outcomes regardless of treatment with an NSAID.

In conclusion, in our study of subjects without known predisposing causes of CME, the increase in postoperative macular thickness was small in both the control and treatment groups. This small increase in macular thickness had no effect on final BCVA in either group. Advances in technology now allow ophthalmologists to quickly evaluate the macula with very high resolution and detect changes that are not clinically apparent at the slit lamp. Although this information is useful, the clinician must remember that visual function is most important when evaluating macular oedema. ${ }^{27}$ Therefore, because ultimate BCVA was excellent in both groups, our study does not support the routine use of postoperative nepafenac when preoperative nepafenac is used.

\section{Acknowledgements}

We thank Gary G Koch, PhD, Professor of Biostatistics, Biostatistics Consulting Laboratory, School of Public Health, University of North Carolina at Chapel Hill, for providing statistical support.

\section{References}

1 O'Brien TP. Emerging guidelines for use of NSAID therapy to optimize cataract surgery patient care. Curr Med Res Opin 2005; 21: 1131-1137.

2 Henderson BA, Kim JY, Ament CS, Ferrufino-Ponce ZK, Grabowska A, Cremers SL. Clinical pseudophakic cystoid macular edema: risk factors for development and duration after treatment. J Cataract Refract Surg 2007; 33: 1550-1558.

3 Mentes J, Erakgun T, Afrashi F, Kerci G. Incidence of cystoid macular edema after uncomplicated phacoemulsification. Ophthalmologica 2003; 217: 408-412.

4 Von Jagow B, Ohrloff C, Kohnen T. Macular thickness after uneventful cataract surgery determined by optical coherence tomography. Graefes Arch Clin Exp Ophthalmol 2007; 245: 1765-1771.

5 Wolf EJ, Braunstein A, Stih C, Braunstein RE. Incidence of visually significant pseudophakic macular edema after uneventful phacoemulsification in patients treated with nepafenac. J Cataract Refract Surg 2007; 33: 1546-1549.

6 Rossett L, Chaudhuri J, Dickersin K. Medical prophylaxis and treatment of cystoid macular edema after cataract surgery. The results of meta-analysis. Ophthalmology 1998; 105: 397-405. 
7 Miyake K, Masuda K, Shirato S, Oshika T, Eguchi K, Hoshi $\mathrm{H}$ et al. Comparison of diclofenac and fluorometholone in preventing cystoid macular edema after small incision cataract surgery: a multicenter prospective trial. Jpn J Ophthalmol 2000; 44: 58-67.

8 Chylack Jr LT, Wolfe JK, Singer DM, Leske MC, Bullimore MA, Bailey IL et al. The lens opacities classification system III. Arch Ophthalmol 1993; 111: 831-836.

9 Mathys KC, Cohen KL, Armstrong BD. Determining factors for corneal endothelial cell loss by using bimanual microincision phacoemulsification and power modulation. Cornea 2007; 26: 1049-1055.

10 Fine IH, Packer M, Hoffman RS. Power modulations in new phacoemulsification technology: improved outcomes. J Cataract Refract Surg 2004; 30: 1014-1019.

11 Lobo CL, Faria PM, Soares MA, Bernardes RC, Cunha-Vaz JG. Macular alterations after small-incision cataract surgery. J Cataract Refract Surg 2004; 30: 752-760.

12 Gamache DA, Graff G, Brady MT, Spellman JM, Yanni JM. Nepafenac, a unique nonsteroidal prodrug with potential utility in the treatment of trauma-induced ocular inflammation: I. Assessment of anti-inflammatory efficacy. Inflammation 2000; 24: 357-370.

13 Ke TL, Graff G, Spellman JM, Yanni JM. Nepafenac, a unique nonsteroidal prodrug with potential utility in the treatment of trauma-induced ocular inflammation: II. In vitro bioactivation and permeation of external ocular barriers. Inflammation 2000; 24: 371-374.

14 Sourdille P, Santiago P-Y. Optical coherence tomography of macular thickness after cataract surgery. J Cataract Refract Surg 1999; 25: 256-261.

15 Perente I, Utine CA, Ozturker C, Cakir M, Kaya V, Eren H et al. Evaluation of macular changes after uncomplicated phacoemulsification surgery by optical coherence tomography. Curr Eye Res 2007; 32: 241-247.

16 Biro Z, Balla Z, Kovacs B. Change of foveal and perifoveal thickness measured by OCT after phacoemulsification and IOL implantation. Eye 2008; 22: 8-12.

17 Almeida DR, Johnson D, Hollands H, Smallman D, Baxter S, Eng KT et al. Effect on prophylactic nonsteroidal antiinflammatory drugs on cystoid macular edema assessed using optical coherence tomography quantification of total macular volume after cataract surgery. J Cataract Refract Surg 2008; 34: 64-69.

18 Asano S, Miyake K, Ota I, Sugita G, Kimura W, Sakka Y et al. Reducing angiographic cystoid macular edema and blood-aqueous barrier disruption after small-incision phacoemulsification and foldable intraocular lens implantation. Multicenter prospective randomized comparison of topical diclofenac $0.1 \%$ and betamethasone 0.1\%. J Cataract Refract Surg 2008; 34: 57-63.

19 Donnenfeld ED, Perry HD, Wittpenn JR, Solomon R, Nattis A, Chou T. Preoperative ketorolac tromethamine $0.5 \%$ in phacoemulsification outcomes: pharmacokinetic-response curve. J Cataract Refract Surg 2006; 32: 1474-1482.

20 Ginsburg AP, Cheetham JK, DeGryse RE, Abelson M. Effects of flurbiprofen and midomethacin on acute cystoid macular edema after cataract surgery: functional vision and contrast sensitivity. J Cataract Refract Surg 1995; 21: 82-92.

21 Alio J, Rodriguez-Prats JL, Galal A, Ramzy M. Outcomes of microincision cataract surgery versus coaxial phacoemulsificatoin. Ophthalmology 2005; 112: 1997-2003.

22 Kurz S, Krummenauer F, Gabriel P, Pfeiffer N, Dick HB. Biaxial microincision versus coaxial small-incision clear corneal cataract surgery. Ophthalmology 2006; 113: 1818-1826.

23 Cheng B, Liu Y, Liu X, Ge J, Ling Y, Zheng X. Macular image changes of optical coherence tomography after phacoemulsification. Zhonghua Yan Keza Zhi 2002; 38: 265-267.

24 Massin P, Vicaut E, Haouchine B, Erginay A, Paques M, Gaudric A. Reproducibility of retinal mapping using optical coherence tomography. Arch Ophthalmol 2001; 119: 1135-1142.

25 Ching H-Y, Wong AC, Wong C-C, Woo DC, Chan CW. Cystoid macular oedema and changes in retinal thickness after phacoemulsification with optical coherence tomography. Eye 2006; 20: 297-303.

26 Wittpenn JR, Silverstein S, Heier J, Kenyon KR, Hunkeler JD, Earl M, Acular LS for Cystoid Macular Edema (ACME) Study Group. A randomized, masked comparison of topical ketorolac $0.4 \%$ plus steroid vs steroid alone in low-risk cataract surgery patients. Am J Ophthalmol 2008; 146: 554-560.

27 Kim A, Stark WJ. Are topical NSAIDs needed for routine cataract surgery? Am J Ophthalmol 2008; 146: 483-485. 